\title{
Preface to the Special Issue on "Geomagnetic Research for Taiwan: Present and Future"
}

\author{
Benjamin Fong Chao and Weijia Kuang
}

Citation: Chao, B. F. and W. Kuang, 2015: Preface to the special issue on "geomagnetic research for Taiwan: Present and future". Terr. Atmos. Ocean. Sci., 26, I-II, doi: 10.3319/TAO.2014.10.29.01(GRT)

This special issue documents the status of various aspects on the geomagnetic research in Taiwan with forwardlooking prospects. Geomagnetic experiments and observations conducted in Taiwan can be dated back to the 1970s in their earliest forms. Systematic geomagnetic monitoring and the ensuing research did not emerge until 1988 when the Institute of Earth Sciences of the Academia Sinica began to install continuous magnetometer stations at island-wide locations. Eight proton-precession scalar magnetometers were installed to measure magnetic field intensity at $5-10$ minutes data rates. The reference Lun-Ping station was further upgraded to the INTERMANGNET standard in 1998 (but later closed). A major objective of this geomagnetic network was to monitor earthquake activities, as exemplified in Liu et al. (2001), in conjunction with Taiwan's seismic and GPS networks. The year 1999 saw the devastating Chi-Chi earthquake in central Taiwan. Surprising precursive geomagnetic signals were identified and reported (Yen et al. 2004). More magnetic stations were established with the total number reaching 11 by 2007 . The data rates were improved to 1 minute and then $1 \mathrm{~s}$ (Yen et al. 2009).

A series of geomagnetic surveys in Taiwan were conducted on land and the adjacent seas. These surveys include the western plains by the China Petroleum Company $(\mathrm{Hu}$ 1981), eastern and southern seismic zones by Academia Sinica (Yu and Tsai 1981), marine geomagnetic anomaly compilation (Hsu et al. 1998), the Tatun volcanic group in northern Taiwan (Chen et al. 2001), and a general survey in the plain and lowland areas (Wang et al. 2002).

In 18 - 20 November 2012, a workshop entitled "Academic Workshop on Earth Sciences" was held at Academia Sinica. It brought together expertise with invited scientists working in broad geomagnetism areas from Academia Sinica and various universities in Taiwan, the Institute of Geology and Geophysics of the Chinese Academy of Sciences (Beijing), and the NASA Goddard Space Flight Center in the USA. The present special issue is a collection of papers presented at the workshop covering a broad range of geomagnetic subjects. Our hope, as was the main purpose of the workshop, is to promote interactions and collaborations, and equally important, to help inspire new interests in the vibrant research discipline of geomagnetic research and application.
We are grateful for the support of the Taiwan Ministry of Science and Technology under grant 103-2116-M-001-024.

\section{REFERENCES}

Chen, K. J., C. M. Wang, S. K. Hsu, and W. T. Liang, 2001: Geomagnetic basement relief of the northern Taiwan area. Terr. Atmos. Ocean. Sci., 12, 441-460.

Hsu, S. K., C. S. Liu, C. T. Shyu, S. Y. Liu, J. C. Sibuet, S. Lallemand, C. Wang, and D. Reed, 1998: New gravity and magnetic anomaly maps in the Taiwan-Luzon region and their preliminary interpretation. Terr. Atmos. Ocean. Sci., 9, 509-532.

Hu, C. C., 1981: Gravity and magnetic studies of the Taoyuan and Hsinchu area, Taiwan. Bull. Geophys. Natl. Cent. Univ., 21, 49-60.

Liu, J. Y., Y. I. Chen, Y. J. Chuo, and H. F. Tsai, 2001: Variations of ionospheric total electron content during the Chi-Chi earthquake. Geophys. Res. Lett., 28, 13831386, doi: 10.1029/2000GL012511. [Link]

Wang, C., C. P. Huang, L. Y. Ke, W. J. Chien, S. K. Hsu, C. T. Shyu, W. B. Cheng, C. S. Lee, and L. S. Teng, 2002: Formation of the Taiwan island as a solitary wave along the Eurasian continental plate margin: Magnetic and seismological evidence. Terr. Atmos. Ocean. Sci., 13, 339-354.

Yen, H. Y., C. H. Chen, Y. H. Yeh, J. Y. Liu, C. R. Lin, and Y. B. Tsai, 2004: Geomagnetic fluctuations during the 1999 Chi-Chi earthquake in Taiwan. Earth Planets Space, 56, 39-45, doi: 10.1186/BF03352489. [Link]

Yen, H. Y., C. H. Chen, H. H. Hsieh, C. R. Lin, Y. H. Yeh, Y. B. Tsai, J. Y. Liu, G. K. Yu, and Y. R. Chen, 2009: Magnetic survey of Taiwan and its preliminary interpretations. Terr. Atmos. Ocean. Sci., 20, 309-314, doi: 10.3319/TAO.2008.04.08.01(T). [Link]

Yu, S. B. and Y. B. Tsai, 1981: Geomagnetic investigations in the Pingtung plain, Taiwan. Bull. Inst. Earth Sci. Acad. Sin., 1, 189-208.

\section{Responsible Editor:}

Cheng-Horng Lin

Institute of Earth Sciences, Academia Sinica, Taipei, 
Taiwan, ROC

E-mail: lin@earth.sinica.edu.tw

\section{Guest Editor:}

\section{Weijia Kuang}

Planetary Geodynamics Laboratory, NASA Goddard Space Flight Center, Greenbelt, Maryland, USA
E-mail: weijia.kuang@gmail.com

\section{Executive Guest Editor:}

Benjamin Fong Chao

Institute of Earth Sciences, Academia Sinica, Taipei, Taiwan, ROC

E-mail: bfchao@earth.sinica.edu.tw 